\section{O Mestrado do Programa de Pós- graduação em Epidemiologia da UFPel baseado em consórcio de pesquisa: uma experiência inovadora}

\section{UFPel's epidemiology MSc program based on research consortium: an innovative experience}

Aluísio J. D. Barros

Ana Maria Baptista Menezes

Iná S. Santos

Maria Cecília F. Assunção

Denise Gigante

Anaclaudia Gastal Fassa

Margarete Marques

Cora Araújo

Pedro C. Hallal

\section{Luiz Augusto Facchini}

Programa de Pós-graduação em Epidemiologia, Universidade Federal de Pelotas

\section{Resumo}

O Programa de Pós-graduação em Epidemiologia da UFPel realizou um intenso trabalho de auto-avaliação para resolver problemas identificados com seu curso de mestrado. O resultado foi a introdução de uma estrutura curricular baseada em dois pilares. De um lado, disciplinas de cunho teórico, fornecendo a base da formação do mestrando; de outro, disciplinas de cunho prático, onde os alunos trabalham coletivamente a construção de seu projeto de pesquisa, passando pela escolha de um tema, revisão da literatura, definição de objetivos e da metodologia. Esse esforço conjunto culmina na realização de um trabalho de campo único, na forma de um estudo transversal de base populacional, em que todos os mestrandos participam de maneira integral, obtendo dados para sua dissertação. Essa estratégia tem garantido a formação de mestres em epidemiologia com forte base teórica e com experiência de preparação e condução de um trabalho de campo. Além disso, tem sido possível manter um tempo de titulação abaixo de 24 meses. Cerca de 80\% dos egressos têm publicado pelo menos um artigo baseado em seu mestrado. Destas publicações, quase $90 \%$ têm se dado em periódicos classificados como Internacional-A no Qualis da Capes.

Palavras-chave: pós-graduação, mestrado, estudos transversais

Correspondência: Aluísio J D Barros. Programa de Pós-graduação em Epidemiologia, UFPel. R. Mal. Deodoro, 1160 3o. piso - 96020-220 Pelotas, RS. E-mail: abarros.epi@gmail.com 
Abstract

The postgraduate program in epidemiology of the Federal University of Pelotas, Brazil, went through an intense self-assessment process to solve problems related to its Master's course. The result was the introduction of a curricular structure based on two pillars. The first one: theoretical courses to offer students the bases of epidemiology. The other, practical training in which students work in groups to design their research projects, from the choice of a research question, to literature review, definition of objectives and methods. This joint effort leads to shared fieldwork, a cross-sectional population-based study, where all students have full participation and get data for their dissertations. This strategy has provided students with strong theoretical background and experience in preparing and conducting fieldwork. Besides, a median completion time below 24 months has been achieved. About $80 \%$ of the students who complete the course published at least one paper based on their dissertations; and almost $90 \%$ of these papers were published in journals classified as A-International by the Qualis criteria established by Capes.

Keywords: post-graduation, masters, cross-sectional studies

\section{Introdução}

O Programa de Pós-graduação (PPG) em Epidemiologia da Universidade Federal de Pelotas foi criado em 1991, como fruto do amadurecimento do trabalho de pesquisa de um grupo de docentes do Departamento de Medicina Social. Inicialmente, foi oferecido o curso de mestrado acadêmico em epidemiologia, que se consolidou rapidamente, tendo alcançado, já em 1995, conceito "A" na avaliação da Capes. Seis anos mais tarde, em 1997, foi criado o curso de doutorado em epidemiologia. $\mathrm{Na}$ avaliação trienal de 2007, o curso recebeu o conceito "7" da CAPES.

O curso de mestrado, em sua proposta original, baseava-se em duas idéias centrais:

- formar epidemiologistas que tivessem experiência de campo e soubessem não só analisar dados, mas também planejar e conduzir estudos de campo; e

- divulgar de forma efetiva os resultados de pesquisas.

A primeira idéia foi contemplada através da exigência de que as dissertações fossem feitas a partir de dados primários, coletados para atender objetivos específicos de projeto de pesquisa planejado e implementado pelo próprio mestrando. A segunda idéia levou à adoção pioneira de um formato de dissertação baseado em artigos. Esse novo formato visava resolver um antigo paradoxo da pós-graduação, que tem como objetivo formar acadêmicos, cuja forma de comunicação com os pares, na área do Programa, é o artigo científico ${ }^{1,2}$, mas cujo treinamento não incluía redação de artigos. Ao invés da produção de uma longa peça acadêmica, a ser lida por um número restrito de pessoas, a dissertação deveria conter dois artigos científicos, além do projeto de pesquisa e de um relatório do trabalho de campo.

Em 1999, com a recente criação do doutorado, foi realizado um cuidadoso trabalho de auto-avaliação, tendo como pano 
de fundo um contexto nacional de formação pós-graduada, que demandava menores prazos de formação, maior produtividade científica de docentes e discentes, e, ao mesmo tempo, não acenava com ampliação no financiamento do sistema, seja na forma de bolsas como no apoio a projetos de pesquisa. Assim, o programa passou por uma profunda reestruturação que visava garantir maior brevidade na titulação, mas preservando suas características básicas - formação teórica de alta qualidade e experiência prática através de coleta de dados primários. Mantendo sua tradição de propostas inovadoras, o mestrado adotou uma estratégia envolvendo a participação de todos os mestrandos em uma única coleta de dados, denominada "consórcio de pesquisa”. Tal estratégia deveria resolver os problemas identificados, simplificando o trabalho de campo dos mestrandos, mas ao mesmo tempo ampliando o tamanho de amostra para cada aluno num estudo de base populacional. A organização e execução de um levantamento de dados em conjunto apresentava, em princípio, a possibilidade de menor gasto de tempo e dinheiro no trabalho de campo, permitindo ao aluno investir mais em atividades formativas - especialmente discussões em seminários com a participação do corpo docente e na sua própria revisão bibliográfica.

A idéia do consórcio é simples, a execução nem tanto, pois implica em uma construção coletiva, culminando em um trabalho de campo comum para o conjunto dos projetos de pesquisa dos mestrandos. No presente artigo descrevemos, em detalhes, a proposta pedagógica do mestrado em epidemiologia, adotada a partir de 1999, utilizando o consórcio em pesquisa. Dá-se ênfase à estrutura e funcionamento do consórcio, em vista do seu aspecto inovador. Apresentamos uma comparação de alguns indicadores, como tempo de conclusão e produção científica, com o período anterior. Aspectos positivos e limitações da nova proposta, juntamente com suas perspectivas de futuro, também são discutidos.

\section{Métodos}

\section{A proposta pedagógica}

Dois eixos principais estruturam o curso de mestrado no seu primeiro ano. De um lado, uma série de disciplinas que contribuem para a formação de uma base de conhecimento da área de epidemiologia e que inclui tópicos em mensuração de saúde e doença, causalidade, desenhos de estudos epidemiológicos, erros e vieses, análise de dados categóricos, contínuos, introdução às ciências sociais, tópicos em demografia, entre outros. De outro, disciplinas de orientação eminentemente prática (práticas de pesquisa) oportunizam a reflexão sobre temas a serem abordados nos projetos individuais dos mestrandos, assim como a tradução do aprendizado teórico para a situação prática de pesquisa. A seleção de um tema de investigação, a revisão bibliográfica e o preparo de um projeto de pesquisa são os assuntos principais deste eixo.

Assegurando a integralidade da formação, o programa promove seminários semanais, onde participam todos os docentes e discentes do programa. Esse momento permite o contato com pesquisadores externos, projetos de pesquisa em curso, debates sobre temas atuais num ambiente democrático de aprendizado, colocando à prova e consolidando os conhecimentos adquiridos pelos mestrandos.

No segundo ano do curso, são oferecidas diversas disciplinas em formato intensivo (segunda a sexta-feira em período integral) cobrindo aspectos variados da pesquisa em saúde - ensaios clínicos, pesquisa qualitativa, modelos lineares generalizados, pesquisa clínica etc. Nesse período, os alunos já têm disponível em mãos os dados de seus projetos e estão trabalhando na análise de dados, no aprofundamento de sua revisão da literatura e na redação do seu artigo. Os seminários de pesquisa seguem em paralelo a essas atividades. 
O consórcio de pesquisa - projeto e instrumentos

O consórcio de pesquisa dos mestrandos tem como espinha dorsal quatro disciplinas bimestrais denominadas Prática de Pesquisa (PP) I-IV. No contexto dessas disciplinas, os alunos recebem orientação, num processo coletivo de construção desde a definição do tema, passando pela revisão de literatura, até o delineamento final de instrumentos e amostra.

Em um primeiro momento (PP I), há uma discussão de temas para cada aluno, dentro de sua área de interesse. A relevância do assunto e sua adequação e exeqüibilidade dentro do contexto do delineamento do estudo a ser realizado, são discutidas em grupo, até que se chegue a uma proposta que atenda a todos esses requisitos. Estas discussões incluem esforços no sentido de compatibilizar populações-alvo e tamanho de amostra para os diferentes temas. Este momento se completa com a elaboração de uma justificativa que demonstre a clara relevância do assunto a ser estudado e o objetivo geral do projeto.

O passo seguinte (PP II) é a redação e estruturação dos projetos de pesquisa propriamente ditos, o que ocorre com o apoio dos docentes da disciplina e dos respectivos orientadores. Ao final do segundo bimestre, cada aluno deverá ter um projeto completo, com uma justificativa que envolva uma revisão da literatura recente e relevante sobre o tema, objetivos gerais e específicos e hipóteses a serem testadas. Questões metodológicas específicas ao projeto devem estar pelo menos indicadas, principalmente em termos de definição operacional do desfecho e das exposições de interesse.

Os projetos são então distribuídos entre os docentes do programa, sendo indicado um revisor para cada aluno. Durante todo o terceiro bimestre, os alunos apresentam seu projeto em seminário para todo o grupo de mestrandos e docentes, sendo argüidos pelo revisor. Este processo de discussão em grupo resulta em um aprimoramento das propostas, de forma que se possa trabalhar na construção do instrumento da pesquisa. Em alguns casos, ampla reformulação da proposta do mestrando acontece, em vista das críticas, comentários e sugestões do revisor, de outros docentes e dos próprios colegas. Este é um momento especialmente rico no processo de formação, onde conhecimento teórico, prático e específico do assunto de pesquisa é utilizado para o aperfeiçoamento dos projetos.

Com o projeto definido, os alunos trabalham, sempre em conjunto, na construção do questionário (PP III). O instrumento é estruturado de forma a incluir um bloco geral, com informações demográficas e socioeconômicas relativas ao domicilio e indivíduos em estudo. Tipicamente, o bloco comum inclui a composição do domicílio - número de moradores, sexo e idade - assim como escolaridade do chefe da família, renda familiar e dados sobre bens domésticos que permitam construir indicadores socioeconômicos, como o Critério de Classificação Econômica Brasil $(\mathrm{CCEB})^{3}$ e o Indicador Econômico Nacional (IEN) ${ }^{4}$. Blocos temáticos englobando as questões definidas pelos alunos são organizados de forma a constituir uma seqüência lógica de perguntas, sem que as questões de cada aluno estejam necessariamente juntas. Sempre que possível, são utilizadas escalas ou instrumentos validados. Ocasionalmente, medidas específicas (acuidade visual de perto ${ }^{5}$, peso e altura ${ }^{6}$, avaliação de lesões dermatológicas ${ }^{7}$, atividade física ${ }^{8}$, etc.) são realizadas em toda a amostra ou em sub-amostras.

A elaboração do instrumento a ser aplicado e o respectivo manual de campo é a atividade principal do terceiro bimestre do curso, sendo que esse processo sempre ocorre em paralelo à revisão e ao aprimoramento do projeto de pesquisa. A disciplina PP IV constitui-se basicamente na coleta de dados no campo, realizada sob a supervisão geral de um docente. Sua descrição detalhada é apresentada a seguir. 


\section{Delineamento do estudo}

O estudo, realizado em conjunto pelos alunos segundo a lógica do consórcio, é constituído de um estudo transversal, de base populacional, abrangendo a zona urbana do município de Pelotas, RS. A população alvo, em termos de sexo e idade, tem variado a cada turma, dependendo do interesse do grupo. Já se estudaram todas as faixas etárias, apenas adultos e idosos etc., sendo sempre a amostra desenhada de forma a ser representativa dos grupos etários escolhidos.

\section{Desenho e tamanho amostral}

Utiliza-se uma amostra em dois estágios, sendo a unidade amostral primária o setor censitário conforme definido pelo IBGE no Censo Demográfico mais recente. A seleção de setores se faz por amostragem sistemática, com probabilidade proporcional ao tamanho, incluindo uma estratificação implícita, através da ordenação dos setores por renda ou escolaridade média do chefe do domicílio9

O tamanho amostral é definido a partir de cálculos para os desfechos de cada um dos alunos - as estimativas para prevalência e associação são calculadas e esses valores inflacionados com base em estimativas prévias da correlação intra-grupo (correção para o desenho amostral). Consórcios anteriores têm fornecido a maioria das estimativas utilizadas nessa correção. Dentro da viabilidade operacional e orçamentária, adota-se o maior tamanho amostral obtido.

O cálculo do tamanho da amostra, assim como o seu delineamento, são realizados em uma oficina, com duração de dois dias, que envolve os docentes da disciplina de PP, os orientadores, os alunos e um professor convidado com larga experiência em amostragem. Nesse momento, aspectos gerais de amostragem, problemas específicos relacionados à amostragem por conglomerados, assim como estratégias para a análise desse tipo de dados, são abordados em sessões teóricas e práticas.

\section{Trabalho de campo}

O curso de mestrado está estruturado de forma que as atividades didáticas são concentradas nas segundas e terças-feiras, com o objetivo de propiciar a participação de alunos não residentes no município. No entanto, na fase do trabalho de campo é exigida dedicação integral dos alunos.

A coleta de dados tem sido financiada, em sua maior parte, com recursos do PROAP, sendo definido a priori o valor a ser aplicado. Havendo necessidade, os alunos complementam esses recursos, de forma a viabilizar a realização do campo. A possibilidade de contratar entrevistadores e digitadores, que são os maiores gastos nesse tipo de estudo, tem ajudado a garantir a rapidez e qualidade do levantamento de dados.

Os mestrandos dividem entre si as tarefas de gestão financeira do estudo, seleção de pessoal (entrevistadores, digitadores), definição do formato final dos instrumentos da pesquisa (questionários, manuais de instrução, planilhas, crachás, termo de consentimento, mapas), providências relativas à impressão, compra e organização do material para o trabalho de campo, elaboração do banco de dados, criação de rotinas de checagem de consistência dos dados, definição do fluxo dos questionários e estrutura de arquivamento.

\section{Treinamento de entrevistadores}

No início do quarto bimestre, uma semana inteira é reservada ao treinamento de entrevistadores e acertos finais no instrumento e manual de campo. Essa atividade é coordenada pelos alunos, sendo cada um responsável pelo treinamento de sua parte específica do questionário. $\mathrm{O}$ treinamento dos entrevistadores consiste na leitura do questionário e manual de instruções, simulação de entrevistas e prova de seleção abordando situações de entrevista. Nesta primeira etapa, ocorre uma pré-seleção de um número suficiente de entrevistadores e suplentes, que participa- 
rão do piloto. O desempenho dos entrevistadores no piloto é considerado para a seleção final da equipe.

\section{Coleta de dados}

Na coleta de dados, os alunos desempenham a função de supervisores de campo, são responsáveis pelo treinamento de entrevistadores, estudo piloto, coordenação da reunião semanal com as entrevistadoras, e também supervisão e controle de qualidade de cerca de 4 setores censitários, incluindo reconhecimento dos setores sob sua supervisão e o sorteio dos domicílios nestes setores. Todo o fluxo de formulários e a correção dos questionários é responsabilidade dos alunos. Além disso, um sistema de plantão mantém pelo menos um mestrando permanentemente disponível para a solução de dúvidas dos entrevistadores e dos problemas no campo.

Os domicílios selecionados são visitados inicialmente pelos mestrandos, de forma a se obter consentimento e registrar a composição do domicílio. Essa estratégia permite o contato dos alunos com os indivíduos e sua realidade, contribui para a qualidade da coleta de dados e também tem impacto importante nos baixos índices de recusas obtidos.

A entrevista é feita diretamente com os indivíduos em estudo, sendo que, habitualmente, a dona da casa responde sua parte e as informações gerais. $\mathrm{O}$ controle de qualidade envolve a revisão de todos os questionários pelos supervisores (mestrandos), contato por telefone com cerca de $50 \%$ dos domicílios que dispõem de uma linha fixa (para confirmar a aplicação completa do questionário) e repetição de cerca de $5 \%$ das entrevistas, utilizando um instrumento reduzido (para avaliar a repetibilidade das respostas). A digitação é realizada utilizando uma estratégia padrão de dupla entrada, simultaneamente à coleta de dados.

Tipicamente, a estratégia de mestrado em consórcio permite que os alunos tenham dados originais e de alta qualidade para análise a partir de fevereiro do ano seguinte ao ingresso, ou seja, em um período de menos de 12 meses. A partir desse momento, o mestrando dedica-se à análise dos dados e redação de um artigo científico baseado nas informações coletadas, sob supervisão de seu orientador.

\section{Resultados}

A primeira turma a utilizar a estratégia de mestrado em consórcio teve início em 1999. A Tabela 1 mostra os diversos temas estudados pelos alunos das quatro turmas (1999-2005) iniciadas após a adoção dessa estratégia, com as respectivas especificações da amostra, faixa etária, número de pessoas e domicílios visitados, duração do trabalho de campo, assim como as perdas e recusas e o tempo até a primeira defesa de cada uma das turmas. Observa-se grande diversificação dos temas, o que se deve ao perfil profissional dos mestrandos que ingressam no curso. A faixa etária da população estudada esteve de acordo com os temas de cada turma.

Apesar de os números de pessoas entrevistadas e dos domicílios visitados não terem variado muito, ao longo dos oito anos de ocorrência do consórcio, atingindo, em média, cerca de 3.500 pessoas e 1.700 domicílios, o número dos setores censitários sorteados nos dois últimos anos (2003 e 2005) foi mais elevado (144 e 120, respectivamente) do que nos anos anteriores, 1999 e 2001 (49 e 80, respectivamente), com o intuito de reduzir o efeito de delineamento que se mostrou muito elevado para algumas variáveis de interesse. O percentual de recusas e perdas das pesquisas realizadas neste período, nunca ultrapassou os $6 \%$.

A média de duração do trabalho de campo tem sido de três meses. Excepcionalmente, na turma de 2005, três meses após o término do trabalho de campo foi detectada fraude em algumas entrevistas de um mesmo entrevistador e decidiu-se sortear três novos setores para substituir aqueles anteriormente incluídos, manten- 
Tabela 1 - Descrição de temas, população, trabalho de campo e defesa de dissertação, no período do consórcio. Mestrado acadêmico em Epidemiologia, UFPel.

Table 1 - Description of themes, population, fieldwork and dissertation presentation, during the consortium period. Academic Epidemiology MSc, UFPel.

\begin{tabular}{|c|c|c|c|c|c|c|c|}
\hline Turmas & $\begin{array}{l}\text { No de } \\
\text { alunos }\end{array}$ & $\begin{array}{l}\text { Temas } \\
\text { estudados }\end{array}$ & $\begin{array}{l}\text { Setores; } \\
\text { domicílios; } \\
\text { pessoas }\end{array}$ & População & $\begin{array}{l}\text { Duração } \\
\text { do campo }\end{array}$ & $\begin{array}{l}\text { Recusas } \\
\text { e } \\
\text { perdas }\end{array}$ & $\begin{array}{l}\text { Meses } \\
\text { até a pri- } \\
\text { meira de- } \\
\text { fesa }\end{array}$ \\
\hline 1999 & 14 & $\begin{array}{l}\text { DSTs/AIDS, câncer de pele, } \\
\text { consumo de antimicrobianos, } \\
\text { tabagismo em adolescentes, } \\
\text { consumo de doces na adolescência } \\
\text { e ansiedade auto-referida, } \\
\text { adiposidade abdominal, insônia, } \\
\text { dispepsia, uso de inseticidas, } \\
\text { obesidade e satisfação corporal, } \\
\text { presbiopia e bem-estar psicológico }\end{array}$ & $\begin{array}{l}49 ; \\
2112 ; \\
3934\end{array}$ & $\begin{array}{l}\text { Todas as } \\
\text { idades }\end{array}$ & $\begin{array}{l}\text { outubro/1999- } \\
\text { janeiro/2000 }\end{array}$ & $4,5 \%$ & 20 meses \\
\hline 2001 & 11 & $\begin{array}{l}\text { Lombalgia, DSTs, depressão, prática } \\
\text { de atividades físicas, consumo de } \\
\text { medicamentos, fogachos, preven- } \\
\text { ção do câncer de colo uterino, cân- } \\
\text { cer de mama, déficit cognitivo e } \\
\text { doação de órgãos }\end{array}$ & $\begin{array}{l}80 ; \\
1600 ; \\
3182\end{array}$ & $\geq 20$ anos & $\begin{array}{l}\text { janeiro-maio/ } \\
2002\end{array}$ & $5,6 \%$ & 21 meses \\
\hline 2003 & 16 & $\begin{array}{l}\text { Prevalência de fraturas e utilização } \\
\text { de serviços de fisioterapia, sintomas } \\
\text { miccionais, utilização da bicicleta e } \\
\text { acidentes de trânsito, Diabetes Mellitus, } \\
\text { métodos contraceptivos, atividade física, } \\
\text { Síndrome pré-menstrual, consumo de } \\
\text { psicofármacos, estado nutricional dos } \\
\text { adolescentes, consulta médica e } \\
\text { solicitação de exames complementares, } \\
\text { preferências alimentares em crianças, } \\
\text { enxaqueca, vírus influenza e } \\
\text { hérnia inguinal }\end{array}$ & $\begin{array}{l}144 ; \\
1530 \\
3727\end{array}$ & $\geq 3$ anos & $\begin{array}{l}\text { outubro- } \\
\text { dezembro/ } \\
2003\end{array}$ & $3,8 \%$ & 18 meses \\
\hline 2005 & 16 & $\begin{array}{l}\text { Dor de origem dentária, Síndrome da } \\
\text { Apnéia Obstrutiva do Sono, uso de } \\
\text { fotoprotetor solar, continuidade na } \\
\text { Atenção à Saúde, atividade física e } \\
\text { sedentarismo, hábitos saudáveis de } \\
\text { alimentação, consumo de fibras } \\
\text { alimentares, queimadura solar, } \\
\text { cobertura da solicitação médica } \\
\text { do perfil lipídico e utilização de } \\
\text { serviços odontológicos }\end{array}$ & $\begin{array}{l}120 \\
1597 \\
3353\end{array}$ & $\geq 10$ anos & $\begin{array}{l}\text { outubro- } \\
\text { dezembro/ } \\
2005\end{array}$ & $5,5 \%$ & 19 meses \\
\hline
\end{tabular}

DSTs/AIDS - Doenças sexualmente transmissíves; Síndrome de Imunodeficiência Adquirida (Sexually Tansmissible Dseases; Acquired Immunodeficiency Syndrome)

do assim o tamanho de amostra previamente calculado.

O tempo decorrido entre o ingresso do aluno e a defesa da primeira dissertação tem sido em torno de 19 meses, sendo que o maior período de tempo dentre as cinco turmas foi de 27 meses.

A titulação dos mestrandos, em relação 
ao tempo decorrido nos dois períodos (pré e pós-consórcio) e no grupo como um todo está apresentada na Tabela 2 . No grupo pré-consórcio, a média foi de $30 \pm 6,7$ meses, com amplitude de 20 a 58 meses. Este número foi reduzido na vigência do consórcio, quando a média caiu para $22( \pm 1,8)$ meses, e o tempo máximo para 27 meses.

A Tabela 3 mostra a qualificação dos veículos das publicações de discentes, baseadas nas suas dissertações, conforme a classificação Qualis de periódicos (CAPES) para a Área de Saúde Coletiva. No período do consórcio, em relação ao anterior, as publicações Qualis Internacional-A passaram de $72,3 \%$ para $84,8 \%$, concomitantemente a uma redução nas publicações Qualis Internacional-C.

Observa-se na Tabela 4 que o percentual de alunos que concluíram o curso foi maior após a implantação do consórcio do que na fase anterior (95\% versus $85 \%$ ). Dentre os concluintes, o percentual de publicação variou de $50 \%$ a $100 \%$, nas turmas pré-consórcio, sendo que, nas três primeiras turmas após ter sido iniciado o consórcio estes percentuais variaram de $75 \%$ a $91 \%$. Para a turma que ingressou em 2003, o tempo decorrido até o momento desta publicação foi de 30 meses, podendo ainda ocorrer outras publicações. Para a turma ingressante em 2005, não há ainda tempo suficiente para uma avaliação adequada de suas publicações (Tabela 4). A Figura 1 sugere uma tendência crescente na proporção de periódicos Qualis Internacional-A na produção discente (aumento de $23 \%$ entre 1991 e 2003), que, no entanto, não se mostrou estatisticamente significativa $(\mathrm{p}=0,18)$.

Tabela 2 - Tempo de titulação (meses) dos alunos. Mestrado acadêmico em Epidemiologia, UFPel.

Table 2 - Time to attain certification (months) of Academic Epidemiology MSc students, UFPel.

\begin{tabular}{lccc}
\hline Titulação (meses) & $\begin{array}{c}\text { Todas as turmas } \\
(1991-2005)\end{array}$ & $\begin{array}{c}\text { Pré-consórcio } \\
(1991-1997)\end{array}$ & $\begin{array}{r}\text { Consórcio } \\
(1999-2005)\end{array}$ \\
\hline Tempo mínimo & 19 & 20 & 19 \\
Tempo máximo & 58 & 58 & 27 \\
Média ( \pm DP) & $26( \pm 6,3)$ & $30( \pm 6,7)$ & $22( \pm 1,8)$ \\
Mediana & 24 & 29 & 21 \\
\hline
\end{tabular}

Tabela 3 - Descrição das publicações dos mestrandos, segundo o Qualis de periódicos da CAPES para a área de Saúde Coletiva. Mestrado acadêmico em Epidemiologia, UFPel.

Table 3 - Description of publications by MSc students, according to CAPES' Qualis journal classification in the area of Collective Health. Academic Epidemiology MSc, UFPel.

\begin{tabular}{lcccc}
\hline Classificação & \multicolumn{2}{c}{ Pré-consórcio } & \multicolumn{2}{c}{ Consórcio } \\
& $\mathrm{N}$ & $\%$ & $\mathrm{~N}$ & $\%$ \\
\hline Internacional A & 34 & 72,3 & 39 & 84,8 \\
Internacional A (estrangeiras) & $(9)$ & $(19,1)$ & $(9)$ & $(19,6)$ \\
Internacional B & 1 & 2,1 & 1 & 2,2 \\
Internacional C & 7 & 14,9 & 2 & 4,3 \\
Nacional A & 2 & 4,3 & 2 & 4,3 \\
Nacional B & 1 & 2,1 & 0 & 0 \\
Nacional C & 0 & 0 & 2 & 4,3 \\
Livro & 2 & 4,3 & 0 & 0 \\
Total & 47 & 100,0 & 46 & 100,0 \\
\hline
\end{tabular}


Tabela 4 - Descrição das turmas quanto ao número de alunos que ingressaram, concluíram e publicaram pelo menos um artigo da dissertação. Mestrado acadêmico em Epidemiologia, UFPel.

Table 4 - Description of classes as to number of students who enrolled, completed and published at least one article from dissertations. Academic Epidemiology MSc, UFPel.

\begin{tabular}{|c|c|c|c|c|c|c|}
\hline \multirow[t]{2}{*}{ Turmas } & \multirow{2}{*}{$\begin{array}{c}\text { Ingressaram } \\
\text { N }\end{array}$} & \multicolumn{2}{|c|}{ Concluíram } & \multicolumn{2}{|c|}{ Publicaram } & \multirow{2}{*}{$\begin{array}{c}\text { Artigos } \\
\text { publicados } \\
\mathrm{N}\end{array}$} \\
\hline & & $\mathrm{N}$ & $\%$ & $\mathrm{~N}$ & $\%$ & \\
\hline \multicolumn{7}{|c|}{ Pré-consórcio } \\
\hline 1991 & 9 & 8 & 89 & 4 & 50 & 10 \\
\hline 1993 & 12 & 10 & 83 & 7 & 70 & 12 \\
\hline 1995 & 11 & 9 & 82 & 9 & 100 & 15 \\
\hline 1997 & 16 & 14 & 88 & 9 & 64 & 10 \\
\hline Subtotal & 48 & 41 & 85 & 29 & 70 & 47 \\
\hline \multicolumn{7}{|c|}{ Consórcio } \\
\hline 1999 & 16 & 14 & 88 & 11 & 79 & 17 \\
\hline 2001 & 11 & 11 & 100 & 10 & 91 & 15 \\
\hline $2003^{a}$ & 16 & 16 & 100 & 12 & 75 & 14 \\
\hline $2005^{b}$ & 17 & 16 & 94 & - & - & - \\
\hline Subtotal & 60 & 57 & 95 & 31 & 76 & 46 \\
\hline Total & 108 & 98 & 91 & 62 & $79^{c}$ & 93 \\
\hline
\end{tabular}

${ }^{a}$ Menor tempo de exposição para publicar, pois a titulação ocorreu no máximo há 30 meses

a Less exposure time for getting published, because certification was attained less than 30 months before

${ }^{\mathrm{b}}$ Tempo insuficiente para publicar, pois a titulação ocorreu no máximo há 5 meses

${ }^{b}$ Insufficient time for getting published, because certification was attained less than 5 months before

' Percentual calculado pelo total de concluintes até 2003

'Percentage calculated by total of individuals who completed up to 2003

\section{$\square$ Internacional A $\quad \square$ Outras}

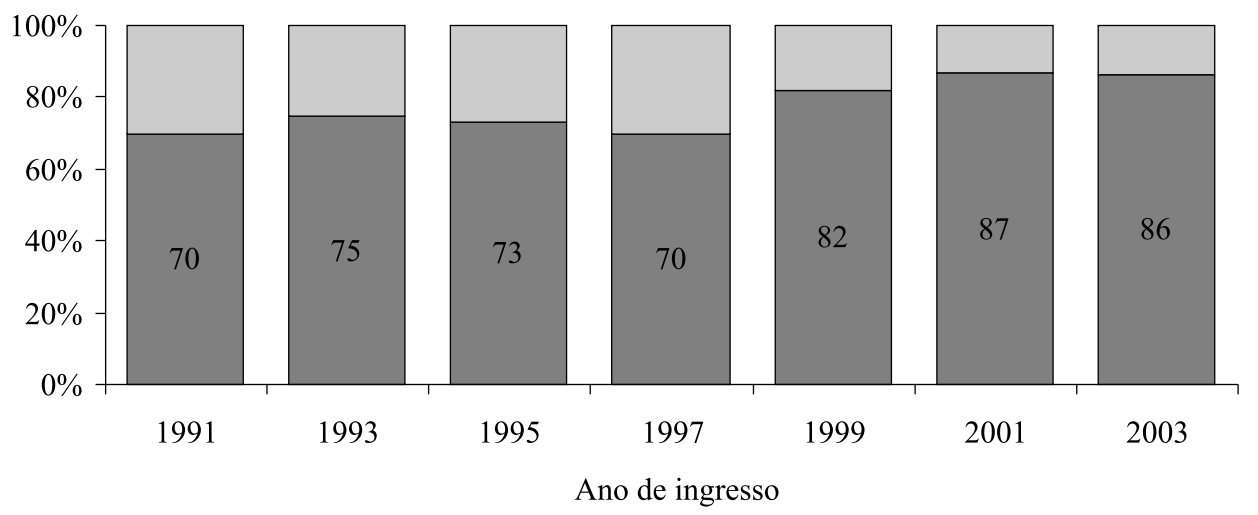

Figura 1 - Proporção de publicações, conforme Qualis de periódicos da CAPES, área da Saúde Coletiva. Mestrado acadêmico em Epidemiologia, UFPEL.

Figure 1 - Proportion of publications, according to CAPES' Qualis classification, in the area of Collective Health. Academic Epidemiology MSc, UFPEL.

\section{Discussão}

Após oito anos do início do mestrado acadêmico em epidemiologia da UFPel, buscou-se encontrar um método que fos- se capaz de otimizar os recursos, financeiros e humanos, para a formação dos alunos. A partir de 1999 o curso foi profundamente reformulado, sendo a característica mais marcante a implementação do 
consórcio de mestrandos para o trabalho de campo, acompanhada de uma série de modificações na estrutura do curso, assim como nas disciplinas. Assim, foram instituídas as Práticas de Pesquisa I-IV (PP IIV) através das quais cada aluno vai construindo seu projeto de dissertação. Embora haja um trabalho de campo comum, a liberdade de cada aluno escolher seu tema de estudo manteve-se preservada. Além disso, durante as disciplinas de Prática de Pesquisa todos os alunos participam das discussões e decisões relativas às propostas de dissertações dos colegas, o que constitui um aprendizado mais amplo do que cada um estar focalizado exclusivamente no seu objeto de pesquisa. Esse benefício do consórcio amplia-se ainda mais, na medida em que os alunos ingressantes no mestrado têm origem em diferentes áreas de graduação, diversificando os temas escolhidos e as discussões para definição final dos objetos individuais de estudo. A participação intensiva de docentes nessa atividade, assim como o processo de apresentação e discussão das propostas de projeto em seminários, com a participação de todo o corpo docente do programa, amplia ainda mais o conjunto de oportunidades de aprendizado dos alunos.

A maior diferença observada entre os períodos pré e pós-consórcio foi a redução na média do tempo de titulação e também em sua variabilidade. No entendimento do corpo docente do programa isso se deu principalmente em função da redução do tempo do trabalho de campo, e sem prejuízo da formação e da maturação dos alunos. Atualmente, menos tempo e esforço são despendidos com a obtenção de recursos, organização e execução do trabalho de campo, deixando o aluno com mais tempo para leitura, análise e redação. É possível até mesmo que o nível de sofrimento psicológico (10), descrito em alunos de pós-graduação, possa ter se reduzido no que tange ao trabalho de campo, em função do trabalho coletivo.

Observou-se também um aumento na publicação de artigos em revistas Qualis
Internacional-A, dado bastante positivo, que revela que a qualidade e relevância da produção científica discente manteve ou melhorou seu padrão. Não se observou redução na produção discente total, que poderia ter ocorrido em função da redução da exigência da produção de dois para um artigo.

Uma outra vantagem da estratégia é a maior possibilidade de controle sobre a qualidade metodológica das dissertações. Sendo o consórcio um estudo único, todos os orientadores participam da elaboração da metodologia. Além disso, a utilização de amostras grandes, com base populacional, garante aos resultados uma relevância que não se teria em estudos baseados em amostras de oportunidade - comuns em dissertações de mestrado, que acabam por utilizar pacientes de um determinado serviço, ou alunos de uma instituição, por exemplo. Normalmente, a realização isolada do campo não permite aos alunos uma amostra com as características daquela obtida através do consórcio.

A oficina de amostragem permite que todos os alunos participem do processo complexo de seleção de uma amostra representativa da população do município. A estratégia do consórcio permite ainda a realização de estudos com faixas etárias diferenciadas. Devido ao grande número de domicílios amostrados em cada consórcio, já foram realizados estudos específicos com crianças, adolescentes, adultos ou idosos, com tamanho de amostra que garantisse poder estatístico para as análises individuais.

O trabalho em equipe é um dos pontos-chave da estratégia em consórcio. Os alunos têm a oportunidade de desenvolver o espírito de trabalho em grupo e as diferenças individuais devem ser resolvidas para o bom andamento do campo. Esse treino é muito importante para a vida futura do aluno, que, seja na academia, seja no serviço de saúde, deverá ser capaz de trabalhar em equipe, de forma harmoniosa e organizada.

A estratégia do consórcio também 
apresenta limitações. A impossibilidade de estudos mais aprofundados sobre temas específicos é ocasionalmente relatada pelos alunos e orientadores. No entanto, a alternativa de realização de sub-estudos pode auxiliar na resolução de tal problema. Por exemplo, um estudo transversal no formato do consórcio sobre sintomas miccionais gerou também um sub-estudo com a aplicação de um questionário detalhado para as mães e tratamento das crianças sintomáticas com um medicamento ${ }^{11}$. Outra limitação é a impossibilidade de dissertações baseadas em dados pré-existentes. Deve-se lembrar, porém, que esta é uma proposta do mestrado desde a sua criação em 1991, não sendo uma limitação específica do período pós-consórcio.

A realização de repetidos estudos populacionais no município tem levantado o temor de que se acabe por ocasionar a saturação da população em termos de pesquisas. No entanto, a população mais pobre, grande maioria no Brasil, mostrase sempre muito solícita em colaborar. E a realização de estudos seriados em Pelotas tem permitido a avaliação de tendências temporais na saúde da população. Por exemplo, já foram realizados estudos sobre a evolução no consumo de psicofármacos e cobertura do exame preventi- vo do câncer de colo de útero ${ }^{12,13}$.

A experiência aqui relatada foi considerada de grande êxito pelos docentes do programa e pelos alunos que já passaram por ela. Acreditamos que compartilhá-la é muito importante, tendo total clareza de que não constitui "receita” a ser copiada. Afinal, esta é uma solução encontrada para uma situação específica. Mas, temos a certeza de que muitos aspectos podem interessar a outros programas de pós-graduação, sendo incorporados e adaptados de maneira inteligente e criativa às suas condições locais. Sabemos que vários programas têm adotado sistemas de mini-consórcios, nos quais alguns alunos - normalmente de uma mesma área de concentração ou linha de pesquisa - realizam estudos simultâneos, que englobam numa única coleta de dados suas dissertações ou teses.

Concluindo, considera-se que o sistema de consórcio trouxe importantes vantagens, tanto do ponto de vista da formação dos alunos como do custo e agilidade na elaboração e conclusão das dissertações. É possível, no entanto, que em futuro próximo seja necessário proceder algum redirecionamento nessa estratégia, de forma a adequá-la às necessidades do programa, dos mestrandos e da população do município.

\section{Referências}

1. Guimarães R, Lourenço R, Cosac S. A pesquisa em epidemiologia no Brasil. Rev Saúde Pública 2001; 35: 32140.

2. Barata RB, Goldbaum M. Perfil dos pesquisadores com bolsa de produtividade em pesquisa do CNPq da área de saúde coletiva. Cad Saúde Pública 2003;19(6):1863-1876. doi: 10.1590/S0102-311X2003000600031.

3. ABEP. Critério de Classificação Econômica Brasil. S. Paulo: Associação Brasileira de Empresas de Pesquisa; 2003. URL: http://www.abep.org/?usaritem=arquivos\& iditem=23 (Acessado em 4 de outubro de 2007).

4. Barros AJ, Victora CG. A Nationwide Wealth Score Based on the 2000 Brazilian Demographic Census. Rev Saúde Pública 2005; 39(4): 523-29. doi: 10.1590/S003489102005000400002 .
5. Duarte WR, Barros AJ, Dias da Costa J, Cattan JM. Prevalência de deficiência visual de perto e fatores associados: um estudo de base populacional. Cad Saúde Pública 2003; 19(2): 551-9.

6. Silveira EA, Araujo CL, Gigante DP, Barros AJ, Lima MS. [Weight and height validation for diagnosis of adult nutritional status in southern Brazil]. Cad Saúde Pública 2005; 21(1): 235-45.

7. Rocha F, Menezes AM. Especificidade e sensibilidade de rastreamento para lesões cutâneas pré-malígnas e malignas Rev Saúde Pública 2002; 36(1): 101-06.

8. Hallal PC, Victora CG, Wells JC, Lima RC. Physical inactivity: prevalence and associated variables in Brazilian adults. Med Sci Sports Exerc 2003; 35(11): 1894900. 
9. Silva NN. Amostragem Probabilística. S. Paulo: Edusp; 1998.

10. Louzada RC, Silva Filho JF. Formação do pesquisador e sofrimento mental: um estudo de caso. Psicologia em Estudo 2005; 10(3): 451-61.

11. Mota DM, Victora CG, Hallal PC. Investigação de disfunção miccional em uma amostra populacional de crianças de 3 a 9 anos. J Pediatr 2005; 81(3): 225-32.
12. Rodrigues MAP, Facchini LA. Modificações nos padrões de consumo de psicofármacos em localidade do Sul do Brasil. Rev Saúde Pública 2006; 40(1): 107-14.

13. Quadros CAT, Victora CG, Dias da Costa J. Coverage and focus of a cervical cancer prevention program in southern Brazil. Rev Panam Salud Publica 2004; 16(4): 223-32. 